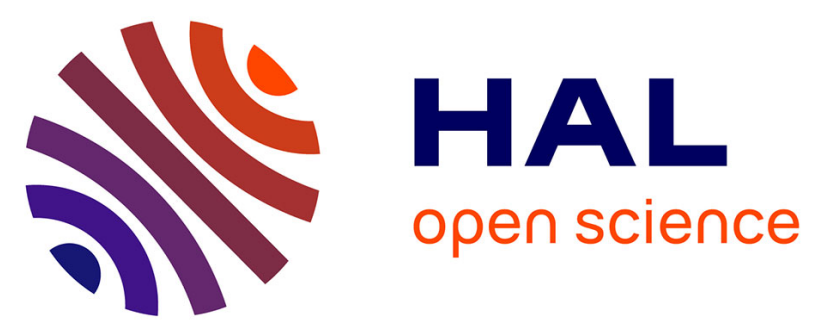

\title{
In-vitro and in-vivo antileishmanial activity of inexpensive Amphotericin B formulations: Heated Amphotericin B and Amphotericin B-loaded microemulsion
}

Andreza Rochelle, Vale Morais, André Leandro Silva, Andreza Rochelle Do Vale Morais, André Leandro Silva, Sandrine Cojean, Kaluvu Balaraman, Christian Bories, Sébastien Pomel, Gillian Barratt, et al.

\section{- To cite this version:}

Andreza Rochelle, Vale Morais, André Leandro Silva, Andreza Rochelle Do Vale Morais, André Leandro Silva, et al.. In-vitro and in-vivo antileishmanial activity of inexpensive Amphotericin B formulations: Heated Amphotericin B and Amphotericin B-loaded microemulsion. Experimental Parasitology, 2018, 192, pp.85-92. 10.1016/j.exppara.2018.07.017 . hal-02370461

\author{
HAL Id: hal-02370461 \\ https://hal.science/hal-02370461
}

Submitted on 19 Nov 2019

HAL is a multi-disciplinary open access archive for the deposit and dissemination of scientific research documents, whether they are published or not. The documents may come from teaching and research institutions in France or abroad, or from public or private research centers.
L'archive ouverte pluridisciplinaire HAL, est destinée au dépôt et à la diffusion de documents scientifiques de niveau recherche, publiés ou non, émanant des établissements d'enseignement et de recherche français ou étrangers, des laboratoires publics ou privés. 
1 In-vitro and in-vivo antileishmanial activity of inexpensive Amphotericin B formulations:

2 heated Amphotericin B and Amphotericin B-loaded microemulsion

3 Running title: Antileishmanial activity of Amphotericin B formulations

4 Andreza Rochelle do Vale Morais ${ }^{\mathrm{a}, \mathrm{c}}$, André Leandro Silva ${ }^{\mathrm{b}, \mathrm{c}}$, Sandrine Cojean ${ }^{\mathrm{d}}$, Kaluvu

5 Balaraman $^{\mathrm{d}, \mathrm{e}}$, Christian Bories ${ }^{\mathrm{d}}$, Sébastien Pomel $^{\mathrm{d}}$, Gillian Barratt ${ }^{\mathrm{c}}$, Eryvaldo Sócrates Tabosa 6 do Egito $^{\mathrm{a}, \mathrm{b}}$, Philippe M Loiseau ${ }^{\mathrm{d} \#}$

7 a Universidade Federal do Rio Grande do Norte (UFRN), Programa de Pós-graduação em 8 Nanotecnologia Farmacêutica, Rua Gustavo Cordeiro de Farias, SN. Petrópolis. CEP: 59012$9570 \mathrm{Natal} / \mathrm{RN}-$ Brazil.

$10{ }^{\mathrm{b}}$ UFRN, Programa de Pós-graduação em Biotecnologia (RENORBIO), Av. Senador Salgado 11 Filho, 3000. Campus Universitário. CEP: 59078-970 Natal/RN - Brazil

$12{ }^{\mathrm{c}}$ Université Paris-Sud, Institut Galien Paris-Sud, UMR-CNRS 8612, 5, Rue Jean-Baptiste 13 Clément, 92296 Châtenay-Malabry cedex, France.

14 d Université Paris-Sud, Faculté de Pharmacie, UMR 8076 CNRS BioCIS, Châtenay-Malabry, 15 France

$16{ }^{\mathrm{e}}$ Chemical Biology Lab, Department of Biotechnology, IITM, Technology Madras, Chennai, 17 India

${ }^{\#}$ Corresponding author

21 Prof. Philippe M. LOISEAU

22 philippe.loiseau@u-psud.fr 
23 Antiparasitic Chemotherapy, UMR 8076 CNRS BioCIS, Faculty of Pharmacy, Université

24 Paris-Sud

25 Rue Jean-Baptiste Clément, F 92290- Chatenay-Malabry

26 
Amphotericin B (AmB) is effective against visceral leishmaniasis (VL), but the renal toxicity of the conventional form, mixed micelles with deoxycholate (M-AmB), is often dose-limiting, while the less toxic lipid-based formulations such as AmBisome ${ }^{\circledR}$ are very expensive. Two different strategies to improve the therapeutic index of $\mathrm{AmB}$ with inexpensive ingredients were evaluated on this work: (i) the heat treatment of the commercial formulation (H-AmB) and (ii) the preparation of an AmB-loaded microemulsion (ME-AmB). M-AmB was heated to $70^{\circ} \mathrm{C}$ for $20 \mathrm{~min}$. The resulting product was characterized by UV spectrophotometry and circular dichroism, showing super-aggregates formation. ME-AmB was prepared from phosphate buffer pH 7.4, Tween $80^{\circledR}$, Lipoid $\mathrm{S} 100^{\circledR}$ and Mygliol $812^{\circledR}$ with AmB at $5 \mathrm{mg} / \mathrm{mL}$. The droplet size, measured by dynamic light scattering, was about $40 \mathrm{~nm}$ and transmission electron microscopy confirmed a spherical shape. Rheological analysis showed low viscosity and Newtonian behavior. All the formulations were active in vitro and in vivo against Leishmania donovani (LV9). A selectivity index $\left(\mathrm{CC}_{50}\right.$ on $\mathrm{RAW} / \mathrm{IC}_{50}$ on LV9) higher than 10 was observed for ME-AmB, H-AmB and AmBisome ${ }^{\circledR}$. Furthermore, no important in vivo toxicity was observed for all the samples. The in-vivo efficacy of the formulations after IV administration was evaluated in Balb/C mice infected with LV9 (three doses of $1 \mathrm{mg} / \mathrm{kg}$ AmB) and no significant difference was observed between $\mathrm{H}-\mathrm{AmB}, \mathrm{M}-\mathrm{AmB}, \mathrm{ME}-\mathrm{AmB}$ and AmBisome $^{\circledR}$. In conclusion, these two inexpensive alternative formulations for AmB showing good efficacy and selectivity for Leishmania donovani merit further investigation. 
Leishmaniasis is a parasitic infectious disease caused by obligate intra-macrophage 51 protozoa of the Leishmania species, transmitted to humans via the bite of female sand flies of 52 the genera Phlebotomus and Lutzomyia. This disease is widespread in tropical and subtropical 53 areas as three different clinical manifestations: mucocutaneous, cutaneous, and visceral leishmaniasis (VL), also known as kala-azar, which is fatal if untreated (1). Pentavalent antimonials are the most commonly used drugs to treat VL; however, they are no longer recommended due to their toxicity and the emergence of drug resistance (2). Amphotericin B $(\mathrm{AmB})$ and miltefosine are the two alternative drugs able to replace antimonials, although neither drug is completely safe (3). This work is focused on the exploitation of AmB as lowcost and low-toxic formulations.

$\mathrm{AmB}$ has been used as a second-line drug for leishmaniasis treatment (4). Despite its high efficacy, toxic effects, such as cardiotoxicity and nephrotoxicity, limit its successful therapeutic use. The AmB selectivity and toxicity level depend on its aggregation state, which can exist as monomeric, aggregated and super-aggregated states. In order to reduce the side effects credited to AmB, several lipid formulations have been developed. These systems prevent the $\mathrm{AmB}$ self-aggregation and slowly release $\mathrm{AmB}$ monomers to the surrounding medium (5). An example of success on the lipidic approach is the liposomal AmB formulation (AmBisome $^{\circledR}$ ), which is less toxic than Fungizone ${ }^{\circledR}$, the commercial available micellar AmB (M-AmB). Nevertheless, AmBisome ${ }^{\circledR}$ is not widely available due to its cost.

To summarize, the current visceral leishmaniasis treatment remains limited by the 70 issues of drug resistance, toxicity and high cost (6). The therapeutic properties and 
71 pharmacological profile of $\mathrm{AmB}$ can be optimized by modifying the aggregation state of the 72 drug (7) and by developing new drug delivery systems. M-AmB has good availability and relatively low cost; hence it is the most widely used AmB-based product. However, the presence of $\mathrm{AmB}$ in the aggregated state allows the formation of ion channels in membranes containing cholesterol, which causes toxicity (8). Studies have shown that the heating of $\mathrm{M}-\mathrm{AmB}$ is capable of inducing a new type of aggregate, called super-aggregates, which is less selective for the cholesterol in the mammalian cell membranes. Therefore, the toxicity can be significantly reduced without loss of activity $(5,7,9,10)$. The molecular rearrangement that yields super-aggregate structures can be achieved by appropriate heating of $\mathrm{M}-\mathrm{AmB}(5,11)$.

An alternative formulation without the drawbacks of cost and toxicity could be a microemulsion (ME). Microemulsions are anisotropic, clear, small droplet sized and thermodynamically stable drug delivery systems, comprised of an oil and aqueous phase, stabilized by surfactants (12). The ME would be able to carry AmB (ME-AmB) in its dispersed phase, increasing its solubilization and bioavailability, and decreasing its toxicity $(13,14)$.

The aim of this work was to investigate Heated M-AmB (H-AmB) and ME-AmB in comparison with $\mathrm{M}-\mathrm{AmB}$ and $\mathrm{AmBisome}{ }^{\circledR}$ with regard to their in-vitro and in-vivo safety and antileishmanial activity against Leishmania donovani, in order to improve the therapeutic index of AmB while using inexpensive ingredients. 


\section{Chemicals}

Micellar AmB (Anforicin $B^{\circledR}$ ) was a gift from Cristália (Itapira, Brazil). Liposomal AmB (AmBisome ${ }^{\circledR}$ ) was purchased from Gilead (Foster City, USA). Miglyol ${ }^{\circledR}$ 812, used as the oil phase of the ME, was obtained from CONDEA Chemie GMBH (Hamburg, Germany). Lipoid $^{\circledR}$ S100, used as surfactant, was purchased from LIPOID GMBH (Ludwigshafen, Germany). The AmB, used to load the ME, Tween ${ }^{\circledR}$ 80, used as surfactant, $\mathrm{NaH}_{2} \mathrm{PO}_{4}$ and $\mathrm{Na}_{2} \mathrm{HPO}_{4}$, used to prepare the phosphate buffer $\mathrm{pH}$ 7.4, were all acquired from Sigma Aldrich Inc (St. Louis, USA).

\section{Sample preparation}

AmBisome $^{\circledR}$ was prepared according to the manufacturer's instructions. The commercial $\mathrm{M}-\mathrm{AmB}$ was prepared by adding $10 \mathrm{~mL}$ of water for injection into the vial containing $50 \mathrm{mg}$ of $\mathrm{AmB}$ (final concentration of $5 \times 10^{-3} \mathrm{M}$ ), followed by vortex shaking until dissolution. In order to obtain the $\mathrm{H}-\mathrm{AmB}$, the $\mathrm{M}-\mathrm{AmB}$ was heated at $70^{\circ} \mathrm{C}$ for $20 \mathrm{~min}$.

In order to prepare the ME, $68 \%(\mathrm{w} / \mathrm{w})$ of phosphate buffer $\mathrm{pH} 7.4,14.7 \%(\mathrm{w} / \mathrm{w})$ of Tween $^{\circledR} 80,6.3 \%(\mathrm{w} / \mathrm{w})$ of Lipoid $^{\circledR}$ S100 and $11 \%(\mathrm{w} / \mathrm{w})$ of Miglyol ${ }^{\circledR} 812$ were weighed. They were mixed under magnetic stirring followed by 3 cycles of probe sonication ( 80 watts power output) in a Branson Digital Sonifier S-250 (Branson Ultrasonic Corporation - Danbory, USA) for $1.5 \mathrm{~min}$ and followed by $3 \mathrm{~min}$ in a 1210E-MTH Bransonic Ultrasonic bath (Branson Ultrasonic Corporation - Danbory, USA). To incorporate AmB into the ME, solid AmB was added to a final concentration of $5 \times 10^{-3} \mathrm{M}$. Then, the system was alkalinized with 
$114 \mathrm{NaOH} 1 \mathrm{M}$ until complete AmB solubilization. After that the loaded ME was neutralized by

115 addition of $\mathrm{HCl} 1 \mathrm{M}$ to a final $\mathrm{pH}$ of 7.4.

\section{M-AmB and H-AmB characterization}

AmB molecules exhibit absorbance bands correlated to their aggregation state in the

$118 \mathrm{UV} /$ Vis range of 300 to $450 \mathrm{~nm}$. A PerkinElmer Lambda $25 \mathrm{UV} / \mathrm{VIS}$ spectrometer (Waltham,

119 MA, USA) was used to analyze AmB-containing samples in $1 \mathrm{~cm}$ path length cuvettes.

120 Samples were diluted in pure water and analyzed immediately after dilution. M-AmB and H-

121 AmB were diluted to $5 \times 10^{-6} \mathrm{M}$ of $\operatorname{AmB}(5,13)$.

Circular dichroism (CD) spectra were recorded with a Jasco J-180 dichrograph

123 (Easton, MD, USA). Samples were diluted in water to $5.10^{-5} \mathrm{M} \mathrm{AmB} 24 \mathrm{~h}$ before analysis.

124 Measurements were conducted at room temperature using a $0.1 \mathrm{~cm}$ path length cuvette (15).

125 Results are expressed as $\Delta \mathcal{E}$ (differential molar absorption dichroic coefficient).

\section{Microemulsion characterization}

Droplet size distribution analyses were carried out by Dynamic Light Scattering (DLS) using a Malvern-Zetasizer Nano ZS (Malvern, UK). Transmission electron microscopy

129 (TEM) was used to investigate the ME morphology. The MEs was observed after staining

130 with $2 \%$ phosphotungstic acid, using a JEOL 1400 apparatus (SamXPlus, France), operated at

$13180 \mathrm{kV}$ as the acceleration voltage, equipped with a high resolution CCD Gatan digital camera

132 (SC1000 Orius, France). Before performing both types of analysis, the MEs were diluted 1:20

133 with water.

135 rheometer equipped with $35 \mathrm{~mm}$ cone-plate geometry (Thermo Scientific, USA). The flow 
136 curve and the viscosity curve of the samples were performed by controlled shear rate rotation

137 tests (from $0.1 \mathrm{~s}-1$ to $1000 \mathrm{~s}-1$ ).

The aggregation state of the $\mathrm{AmB}$ in the $\mathrm{ME}-\mathrm{AmB}$ was also evaluated by spectrophotometry and CD as described above.

\section{In vitro antileishmanial activity}

142 of the AmB-resistant (AmB-R) strain obtained from the wild-type parasites by in-vitro drug

143 pressure were grown in M-199 medium supplemented with $40 \mathrm{mM}$ HEPES, $100 \mu \mathrm{M}$

144 adenosine, $0.5 \mathrm{mg} / \mathrm{L}$ haemin, and $10 \%$ heat-inactivated fetal bovine serum (FBS) at $26{ }^{\circ} \mathrm{C}$ in a

145 dark environment under an atmosphere of $5 \% \mathrm{CO}_{2}$. Parasites in their logarithmic phase of

146 growth were used for all experiments. Promastigotes were grown at $37{ }^{\circ} \mathrm{C}$ in $5 \% \mathrm{CO}_{2}$

147 atmosphere for 24 hours before treatment for differentiation. The axenic amastigotes were

148 generated by differentiation of promastigotes. To achieve this, a $1 \times 10^{6}$ promastigote

149 suspension was diluted in 5mL of axenic amastigote media (1 X M-199, 40 mM HEPES, 100

$150 \mu \mathrm{M}$ adenosine, $0.5 \mathrm{mg} / \mathrm{L}$ haemin, $2 \mathrm{mM} \mathrm{CaCl} 2,2 \mathrm{mM} \mathrm{MgCl} 2$ and $20 \% \mathrm{FBS}$ ) and the $\mathrm{pH}$ was

151 adjusted to $\mathrm{pH} 6$.

152 Evaluation of the in vitro antileishmanial activity on axenic amastigote stage

153 Axenic amastigotes were suspended at $5 \times 10^{6}$ cells $/ \mathrm{mL}$ in a final volume of $200 \mu \mathrm{L}$.

154 Serial dilutions from 100 to $0.39 \mu \mathrm{g} \mathrm{AmB} / \mathrm{mL}$ was performed by distributing AmBisome ${ }^{\circledR}$, M-

$155 \mathrm{Amb}, \mathrm{H}-\mathrm{AmB}, \mathrm{ME}-\mathrm{AmB}$, and $\mathrm{ME}$ in 96-well plates. Triplicates were used for each

156 concentration. The viability of the axenic amastigote stage was assessed using the trypan blue

157 exclusion method after a 3-day incubation period at $37{ }^{\circ} \mathrm{C}$, in the dark, under a $5 \% \mathrm{CO}_{2}$ 
atmosphere. Parasite growth was determined by using SYBR Green I (Invitrogen, France), a

159 dye whose fluorescence is greatly enhanced upon contact with the parasite DNA. The plates

160 were frozen 3 times and the DNA was extracted from the plates according to the Direct PCR

161 (cell) protocol (Viagen Biotech Inc, Eurogentec, France). Into the PCR plate $10 \mu \mathrm{L}$ of Lysate

162 and $40 \mu \mathrm{L}$ of direct PCR (cell) supplemented with SYBR green I (5 $\mu \mathrm{L}$ of SYBR Green I / 10

$163 \mathrm{~mL}$ of lysis buffer) were added. Untreated parasites were used as control. The fluorescence

164 was directly evaluated on a Mastercycler ${ }^{\circledR}$ ep realplex real-time PCR system (Eppendorf,

165 France). The program was as follows: $90{ }^{\circ} \mathrm{C}, 1 \mathrm{~min}$ and ramp time of $5 \mathrm{~min}$ to obtain $10{ }^{\circ} \mathrm{C}$,

166 during this period the fluorescence was obtained in continue and in a hold step at $10^{\circ} \mathrm{C}$. The

167 curves of fluorescence were analyzed and the fluorescence at $10^{\circ} \mathrm{C}$ was used to determine the

168 concentrations inhibiting parasite growth by $50 \%\left(\mathrm{IC}_{50}\right)$. Indeed, the $\mathrm{IC}_{50}$, the concentration

169 inhibiting the parasite growth by $50 \%$, was determined using the software in line at 170 http://www.antimalarial-icestimator.net/MethodIntro.htm.

171 Evaluation of the in vitro antileishmanial activity on intramacrophagic amastigotes

RAW 264.7 cells (mouse leukemic monocyte macrophage cells) cultured in DMEM with L-glutamine (Life technologies) and 10\% FBS (Life technologies) were suspended to

174 yield $1.5 \times 10^{5}$ cells $/ \mathrm{mL}$ in $96-w e l l$ plate, in a final volume of $100 \mu \mathrm{L}$. After a $24 \mathrm{~h}$ incubation

175 period, cells were infected by a suspension of 1 x $10^{6}$ Leishmania donovani axenic 176 amastigotes/mL in DMEM, and incubated for $24 \mathrm{~h}$ at $37{ }^{\circ} \mathrm{C}$ in the dark and under a $5 \% \mathrm{CO}_{2}$

177 atmosphere. The free parasites were, then, eliminated by washing and intramacrophagic 178 amastigotes were treated with the same AmB samples and concentrations as those in the assay 179 on axenic amastigotes. After $48 \mathrm{~h}$ of incubation under the same conditions, the experiment 180 was stopped and the plate was treated as for the axenic amastigote stage assay. Each 181 experiment was performed in triplicate (16). Fluorescence was compared to that obtained with 
182 untreated infected and uninfected macrophages and untreated axenic parasites used as 183 controls.

\section{In-vivo evaluation}

\section{In-vivo antileishmanial activity}

animal experiments and were approved by the local committee for animal care $(0858.01 / 2014$, Versailles, France).

A suspension of Leishmania donovani (LV9) amastigotes (1x107/100 $\mu \mathrm{L}$ M199 medium supplemented with $40 \mathrm{mM}$ HEPES, $100 \mu \mathrm{M}$ adenosine and $0.5 \mathrm{mg} / \mathrm{L}$ haemin, $10 \%$ FBS), obtained from infected hamster spleen, was injected into female BALB/c mice (weighing $20 \mathrm{~g}$ ) by intravenous route. The mice were randomly sorted into six groups seven days after the infection. Each group was treated with $100 \mu \mathrm{L}$ of one formulation (AmBisome $^{\circledR}, \mathrm{M}-\mathrm{AmB}, \mathrm{H}-\mathrm{AmB}, \mathrm{ME}-\mathrm{AmB}$ and $\left.\mathrm{ME}\right)$, administered by intravenous route for 3 alternate days $(1 \mathrm{mg} / \mathrm{kg} /$ day $)$. Samples were diluted prior to use with $5 \%$ glucose to give a final AmB concentration of $2 \times 10^{-4} \mathrm{M}$. Animals were sacrificed three days after the end of treatment. Livers and spleens were weighed and drug activity was estimated microscopically by counting the number of amastigotes/500 liver cells in Giemsa stained impression smears to calculate the Leishmania donovani units (LDU) for liver parasite burdens, using the Stauber's formula (17). The mean number of parasites per gram of liver among treatment groups and controls was compared. Three independent counting were performed and the results were expressed as the mean values $\pm \mathrm{SD}$. The parasite burden of treatment groups and controls 
203

were compared using the Kruskal-Wallis nonparametric analysis of variance test for comparing two groups. Significance was established for a $\mathrm{P}$ value $<0.05$.

\section{In vitro cytotoxicity assay}

RAW 264.7 cells maintained in DMEM supplemented with $10 \%$ of heat-inactivated FBS (Life technologies) were seeded to early confluence in a 96-well plate at density of 7500 cell/well and incubated in $5 \% \mathrm{CO}_{2}$ at $37{ }^{\circ} \mathrm{C}$ for $24 \mathrm{~h}$ in a final volume of $100 \mu \mathrm{L}$. Thereafter, M-AmB, H-AmB, ME-AmB, AmBisome ${ }^{\circledR}$ and $\mathrm{ME}$ were added to achieve final AmB concentrations from 0.1 to $108 \mu \mathrm{M}$ and incubated for a further $24 \mathrm{~h}$ under the same conditions. In order to estimate background absorbance due to light scattering, wells without cells, but containing the same concentration of the samples, were analyzed. The cytotoxicity of the formulations was evaluated using the MTS [3-(4,5-dimethyl-2-yl)-5-(3carboxymethoxyphenyl)-2-(4-sulfophenyl)-2H-tetrazolium, inner salt] assay, whereupon 20 $\mu \mathrm{L}$ of MTS solution were added into the wells and incubated for further $2 \mathrm{~h}$. Finally, the absorbance was measured using a 492-nm high-pass filter in a Multiskan MS microwell plate reader (Labsystem, Ramat-Gan, Israel) and the $\mathrm{IC}_{50}$ for each formulation was calculated. For this assay 4 replicates were performed.

\section{In vivo toxicity assay}

Blood samples taken from the mice from the antileishmanial activity experiment were kept at room temperature for about $30 \mathrm{~min}$ and, then, centrifuged at 3,500 g for $10 \mathrm{~min}$. In order to evaluate the renal and liver toxicity, serum was harvested from each blood sample and total serum cholesterol (CHO), alkaline phosphatase (ALP), aspartate aminotransferase 
224 (AST), alanineaminotransferase (ALT), creatinine (CREA) and urea (URE) concentrations

225 were determined by commercially available kits according to the manufacturer's instruction.

\section{Statistical analysis}

227 Statistical analyses were performed by using analysis of variance or Kruskal-Wallis tests

228 (nonparametric), followed by the Tukey's or the Dunn's multiple comparison test. GraphPad

229 Prism5 version (GraphPad Software Inc., La Jolla, CA) was used to perform the analysis.

230 Significance was established for a $\mathrm{P}$ value $<0.05$. 


\section{M-AmB and H-AmB characterization}

234 The UV-Vis spectrum for M-AmB (Figure 1a) showed four main peaks at 329, 367, 388 and $235408 \mathrm{~nm}$. The first peak is credited to the aggregated form of AmB whereas the one at 408 is 236 ascribed to the monomeric form (15). After heat treatment it was observed that H-AmB 237 (Figure 1a) presented similar peaks to $\mathrm{M}-\mathrm{AmB}$ regarding the monomeric form, but the 238 aggregate-related peak underwent a blue shift and became centered on $323 \mathrm{~nm}$ in this 239 preparation. The UV-Vis results were in accordance with those observed by circular 240 dichroism (Figure 1c), in which the doublet related to the AmB aggregation was also blue241 shifted for H-AmB.

\section{Microemulsion characterization}

The produced ME was optically clear with a mean droplet size of $22 \mathrm{~nm}$ for the

244 unloaded ME and $36 \mathrm{~nm}$ for the ME containing AmB, with polydispersity indexes of 0.170 245 and 0.594, respectively, indicating that the addition of AmB led to slightly larger particles. 246 TEM revealed that the droplets were spherical in shape even after the addition of AmB

247 (Figure 2). Furthermore, the average size was similar to the DLS results. The rheological 248 analysis revealed that both the unloaded ME and the ME containing AmB (Figure 3) showed 249 a linear relationship between shear stress and shear rate, which is characteristic of a 250 Newtonian material. The apparent viscosity of the unloaded ME and ME containing AmB 251 were $0.0623 \mathrm{Pas} \pm 0.0101$ and $0.1141 \mathrm{Pas} \pm 0.0049$, respectively, which is low because the 252 ME was of the oil-in-water type. The low viscosity would ensure good syringeability as well 253 as ease of mixing with intravenous fluids using minimum mechanical agitation. The AmB 
molecule showed to be in both aggregated and monomeric forms (Figure $1 \mathrm{~b}$ and 1d), since

255 peaks at $323 \mathrm{~nm}$ (aggregated form), 367, 388 and $408 \mathrm{~nm}$ (monomeric form) were observed.

256 All these results: the small spherical droplet size, the transparency and the low viscosity,

257 allow these samples to be characterized as a true ME system. The incorporation of AmB did 258 not affect these parameters.

\section{Toxicity of the formulations}

The $\mathrm{CC}_{50}$ was evaluated in vitro for each formulation (Table 1). M-AmB showed high

261 toxicity towards RAW cells $\left(\mathrm{CC}_{50} 4.5 \pm 0.4 \mu \mathrm{M}\right)$. However, when this formulation was heated this value increased approximately 8 -folds to $39.8 \pm 3.2 \mu \mathrm{M}$, indicated a decrease in toxicity. In fact, in this study, the toxicity of $\mathrm{H}-\mathrm{AmB}$ was similar to that of AmBisome ${ }^{\circledR}$. On the other hand, although the incorporation of the $\mathrm{AmB}$ into the $\mathrm{ME}$ decreased the $\mathrm{CC}_{50}$ of the 265 formulation compared to the unloaded $\mathrm{ME}$, the cytotoxic effect of $\mathrm{ME}-\mathrm{AmB}\left(\mathrm{CC}_{50} 9.0 \pm 0.3\right)$ 266 was slightly lower than that of M-AmB. significant changes $(p>0.05)$ among the samples for the two transaminase activities levels

269 (AST and ALT) and the creatinine levels. However, all treatments caused a significant increase $(\mathrm{P}<0.05)$ in the urea level except for mice treated with unloaded ME. A significant

271 decrease in this parameter was also observed in the mice treated with the ME and the ME$272 \mathrm{AmB}$ compared to the AmBisome ${ }^{\circledR}$. Furthermore, it is noteworthy that heating of M-AmB 273 slightly decreased the blood urea levels. The ALP value increased significantly with all 274 treatments compared to the untreated group. Nevertheless, the ALP level for the mice treated 275 with the AmBisome ${ }^{\circledR}$ was significantly lower than that of the mice treated with the ME-AmB. 276 The CHO results showed no difference between the ME, the AmBisome ${ }^{\circledR}$ and the untreated 
group. However, M-AmB, H-AmB and ME-AmB caused a significant decrease in this

278 parameter, while the lowest values were observed in the mice treated with the ME-AmB.

279

\section{Antileishmanial activity}

The activity of the formulations against Leishmania donovani was evaluated in vitro and in vivo. The in-vitro assays were performed on both Wild-type (WT) and AmB-R intramacrophagic and axenic amastigotes (Table 1). All formulations, except ME (unloaded microemulsion), showed high activity against WT parasites. ME-AmB and H-AmB yielded lower $\mathrm{IC}_{50}$ values than the $\mathrm{AmBisome}{ }^{\circledR}$ for both amastigote stages. As far as the activity on axenic amastigotes was concerned, all the formulations exhibited lower $\mathrm{IC}_{50}$ compared to the intramacrophage amastigote. However, the $\mathrm{IC}_{50}$ of the AmBisome ${ }^{\circledR}$ did not change significantly $(1.73 \mu \mathrm{M}$ and $1.76 \mu \mathrm{M})$.

The $\mathrm{H}-\mathrm{AmB}$ showed a higher $\mathrm{IC}_{50}$ than the $\mathrm{M}-\mathrm{AmB}$, when the Leishmania was within macrophage, and similar antileishmanial activity $\left(\mathrm{IC}_{50}=0.05 \mu \mathrm{M}\right)$ against the axenic stage. However, the selectivity index for the $\mathrm{H}-\mathrm{AmB}$ was approximately 3 -fold higher than that of the M-AmB. Moreover, the ME-AmB showed a better selectivity index than the M-AmB, although it remained lower than the AmBisome ${ }^{\circledR}$.

Some clinical isolates of Leishmania donovani have shown resistance against the AmB (18). Therefore, the issue of AmB resistance should be considered early in the development of any new AmB delivery system. With this in mind, the formulations were evaluated against both AmB-resistant axenic and intramacrophagic amastigotes. The AmBisome ${ }^{\circledR}$ was active against AmB-resistant intramacrophage amastigotes, but it did not show any activity on AmBresistant axenic amastigote. On the other hand, the other formulations were active in a range from 0.8 to $4 \mu \mathrm{M}$ on both axenic and intramacrophagic amastigotes. The drug pressure to get the AmB-R line was previously carried out using $\mathrm{M}-\mathrm{AmB}$. Indeed, the $\mathrm{IC}_{50}$ value of $\mathrm{M}-\mathrm{AmB}$ 
on the AmB-R line was about 30 times higher than those of the WT, both on axenic and intramacrophage amastigotes. Interestingly, the $\mathrm{IC}_{50}$ values of $\mathrm{H}-\mathrm{AmB}, \mathrm{AmBisome}{ }^{\circledR}$ and $\mathrm{ME}-$ $\mathrm{AmB}$ on the AmB-R intramacrophage amastigotes were only about twice as high as those on the WT. These results suggest that these formulations could be useful for the treatment of AmB-R leishmaniasis.

The in-vivo antileishmanial evaluation was performed on the Leishmania

307 donovani/Balb/C mice model. The percentage of parasite burden reduction in vivo is shown in 308 the Table 2. Whereas the unloaded ME alone did not show good activity in vivo, $\mathrm{M}-\mathrm{AmB}, \mathrm{H}-$ $309 \mathrm{AmB}, \mathrm{ME}-\mathrm{AmB}$ and AmBisome ${ }^{\circledR}$ all reduced the parasite burden greatly, with no significant 310 difference between the formulations. No sign of acute toxicity was observed in the mice and 311 the biological parameters did not show significant toxicity, as shown in Table 2.

\section{DISCUSSION}

The MEs prepared in this study showed a spherical shape and a small droplet size,

315 which is in agreement with other studies that describe these systems as having diameters less 316 than $150 \mathrm{~nm}(12,14)$. Although the addition of AmB to the ME increased its droplet size, 317 probably due to the large molecule size and its deposition on the ME interface, the ME-AmB 318 droplet size remained within the acceptable range. Such small droplets on MEs produce only 319 weak scattering of visible light, and as a result the system is transparent, as observed 320 macroscopically in this work. Moreover, the probability of embolus formation after injection 321 of MEs is insignificant due to their small droplet size (12).

322 Since the nanosized droplets do not interact with each other, the resulting MEs have 323 low viscosity (19). The viscosity analysis is of utmost importance since the parenteral 324 administration of very viscous samples could be painful for the patient. Furthermore, it is well 325 known that the syringeability is affected by the viscosity of the parenteral formulations (20). 
The ME and ME-AmB showed a constant low viscosity and proportionality between shear

327 stress and shear rate, for which they were deemed to behave as Newtonian fluids. As a consequence, they can be considered suitable for the intravenous route. This low viscosity ensures ease of mixing with intravenous fluids with minimum mechanical agitation as well as good syringeability and, therefore, can ensure good patient compliance.

Spectrophotometric studies revealed that after the heating process, super-aggregates

332 are formed from $\mathrm{M}-\mathrm{AmB}$, manifested as a blue-shift in the electronic spectra as well as a 333 decrease on the dichroic doublet, which is also blue-shifted in the spectra of H-AmB (15).

334 When $\mathrm{AmB}$ was loaded into the ME, a pattern similar to $\mathrm{H}-\mathrm{AmB}$ was observed. Since the system was not heated in order to form AmB super-aggregates, the peak at $323 \mathrm{~nm}$ probably 336 represents the association of the AmB with the ME-oil phase. Pham et al, (2014) (21) have 337 shown blue-shifts in the AmB dichroic doublet when the molecule is loaded into liposomes. 338 Our results are in agreement with Silva et al (2013) (22), who have developed ME systems to 339 carry $\mathrm{AmB}$ and have demonstrated peaks of $\mathrm{AmB}$ aggregates and monomers at the same time. 340 However, the aggregate peak is not the same as one observed in our work, supporting the 341 theory of that such a peak is a result of a complex formed between the molecule and the 342 system, which for instance depends on the used raw material, mainly the surfactants. Larabi et 343 al (2004) (23) reported studies in which absorption spectrum and circular dichroism varied 344 according to the proportion of lipid in the formulation. Knowing the aggregation state of the 345 molecule inside the carrier is very important since it influences the drug efficacy and toxicity $346(5,9,13,15,24)$.

347 The treatment of visceral leishmaniasis was dominated by pentavalent antimonials for 348 a long time. However due to their toxicity and adverse side effects, these drugs have 349 progressively been replaced as the first-line treatment by the AmB, which is considered as the 350 best existing drug against this disease. Among the different commercial formulations, 
351 Fungizone $^{\circledR}$ (a mixture of $\mathrm{AmB}$ with deoxycholate in a phosphate buffer) is the most

352 frequently used. However, the liposomal formulation is the most effective and safe, despite its 353 high cost (4).

354 In this work, we have proposed two new formulations of AmB which retain its activity 355 while reducing its toxicity, and are furthermore inexpensive, with costs accessible for patients 356 from the tropical endemic countries and easy to manufacture. Both H-AmB and ME-AmB 357 were thoroughly characterized and shown to be appropriate for parenteral use against visceral 358 leishmaniasis. In order to investigate the antileishmanial activity of these formulations, their $359 \mathrm{IC}_{50}$ in axenic and intramacrophage amastigote were evaluated in vitro, as well as the 360 percentage of reduction of parasite burden in vivo. In addition, the cytotoxicity of the 361 formulations was examined in vitro, allowing calculation of the Selectivity Index, while the 362 toxic effects in vivo were analyzed by assessment of renal and liver function, because the most 363 serious side effect of $\mathrm{AmB}$ is nephrotoxicity (25).

364 Both in-vitro and in-vivo experiments with the WT line demonstrated that, as expected, 365 all formulations containing AmB were effective against Leishmania donovani. On the other 366 hand, despite a moderate effect in-vitro, unloaded ME did not show significant in-vivo 367 antileishmanial activity, proving that it was the addition of AmB that produced this effect. Some differences in the in-vitro effectiveness were observed when comparing the 369 axenic and intramacrophagic amastigotes. The axenic amastigote assay allowed us to evaluate 370 an intrinsic activity on parasites, whereas the intramacrophage amastigote assay demonstrates 371 the ability of the active drug to be delivered through the macrophage membrane, the 372 parasitophorous vacuole membrane and finally into the parasite $(26,27)$. It is noteworthy that 373 AmBisome $^{\circledR}$ was not active against AmB-R axenic amastigotes while the other formulations 374 did have some activity. This result cannot be a result of the ME diameter being less than that 375 of AmBisome ${ }^{\circledR}$ (35 vs $80 \mathrm{~nm}$, respectively) since H-AmB, AmBisome ${ }^{\circledR}$ and ME-AmB had 
similar activities on the WT intramacrophage amastigotes. This observation could be related to the composition of the AmB-R membranes, poor in sterols, more fluid than the WT membranes and, therefore, more stable and less sensitive to a liposomal effect. With the intramacrophagic amastigotes, this difference was not observed since all the formulations after macrophage phagocytosis released $\mathrm{AmB}$ within the parasitiphorous vacuole, probably after fusing with lysosomes. Indeed, AmBisome ${ }^{\circledR}$ is a very stable formulation with cholesterol and a high-transition-temperature phosphatidylcholine making a very impermeable membrane and phosphatidylglycerol forming an electrostatic complex with AmB. It is possible that parasite-derived enzymes are necessary to release the AmB from the liposomes and that the AmB-R parasites have a different enzyme profile and are less efficient at this. On the other hand, AmB may be less strongly associated in M-AmB, H-AmB and ME-AmB. Further studies could be focused on the ME behaviour within the infected macrophages through confocal studies.

M-AmB showed the lowest selectivity index, while $\mathrm{H}-\mathrm{AmB}$ presented the highest index. Therefore, the heating process was capable of considerably reducing the cytotoxicity of $\mathrm{AmB}$ in vitro as demonstrated by the $\mathrm{CC}_{50}$ values. This result is supported by Gaboriau et al. (1997)(28) and Petit et al. (1998) (10) whose have found the mild heating as a simple way to decrease the toxicity of micellar AmB systems. In addition, the therapeutic window between the $\mathrm{IC}_{50}(1.53 \mu \mathrm{M})$ and $\mathrm{CC}_{50}(39.8 \mu \mathrm{M})$ of $\mathrm{H}-\mathrm{AmB}$ is wider than that of $\mathrm{M}-\mathrm{AmB}$, thus improving its safety. It is interesting to mention that $\mathrm{H}-\mathrm{AmB}$ have shown to favor drug uptake by macrophage-like cell line (9). The authors suggest that this fact could be interesting since the macrophage could act as a reservoir, releasing monomeric AmB on the infection site and, thus, improving antiparasitic effect (9). ME-AmB (selectivity index $=10.23$ ) also showed a better selectivity compared to M-AmB. When the selectivity index is greater than 10 , it is generally, considered that the pharmacological efficacy is not due to the in-vitro cytotoxicity 
401 (29), therefore, the incorporation of $\mathrm{AmB}$ in $\mathrm{ME}$ systems was able to improve the 402 effectiveness of the drug.

The potential of the new formulations (H-AmB and ME-AmB) was confirmed by the

404 in-vivo studies, which showed no significant differences in their ability to reduce the parasite 405 burden compared to the AmBisome ${ }^{\circledR}$. In addition, both formulations demonstrated minimal 406 cytotoxicity in vivo.

407 The biochemical evaluation of kidney and liver parameters showed that the untreated 408 infected mice had lower values than those with no parasite burden (reference values were 409 found in (30). Some studies have described a reduction of the serum cholesterol 410 concentrations as a function of the splenic parasite burden, since this organ is responsible for 411 cholesterol biosynthesis (31). An overview of all the biochemical results showed that despite 412 some values, which were statistically different, there was a minimal variation among the 413 groups, showing that none of the formulations induced toxicity at the doses used in this study. 414 Therefore, $\mathrm{ME}-\mathrm{AmB}$ and $\mathrm{H}-\mathrm{AmB}$ were considered safe regarding the limited damage to 415 macrophage and the in vivo evaluation.

416 Furthermore, ME-AmB, M-AmB and H-AmB showed efficiency against AmB-R 417 intramacrophagic amastigotes. AmB-unresponsive cases have been reported at the Rajendra 418 Memorial Research Institute of Medical Sciences (RMRIMS), Bihar, India. These drug419 resistant cases are to be expected due to the very high frequency of AmB use (18). Since 420 visceral leishmaniasis is fatal, the development of new systems, which do not demonstrate 421 drug resistance is very important to ensure that suitable treatment would be available. 422 Therefore, these two inexpensive alternative formulations for AmB showing good efficacy 423 and selectivity for Leishmania donovani merit further investigation. Unfortunately, it was not 424 possible to verify the in-vivo efficacy of the formulations on an AmB-R/ mice model since the 425 AmB-R parasites are poorly infectious for Balb/c mice (32). 
427 These experiments show a novel approach to AmB therapy, addressing both the cost of 428 formulations and the AmB-resistance. The formulations $\mathrm{H}-\mathrm{AmB}$ and $\mathrm{ME}-\mathrm{AmB}$ proved to be 429 very successful in the treatment of a Leishmania donovani Balb/c mouse model. Both in-vivo 430 and in-vitro evaluations showed good efficacy and low toxicity for these formulations. Since 431 the method of preparing the $\mathrm{H}-\mathrm{AmB}$ is just the heating of the reconstituted M-AmB for a few 432 minutes, it appears to be a low cost alternative to the commercially available products. The 433 cost of producing MEs is also lower than that of producing the liposomal AmB, since the 434 components are commonly used pharmaceutical excipients rather than expensive 435 phospholipids. Therefore, the formulation developed in this work is a promising way to 436 reduce toxicity while maintaining the efficacy of AmB.

\section{ACKNOWLEDGEMENTS:}

438 The authors wish to thank the CAPES-Cofecub and CNPq for the financial support. Kaluvu 439 Balaraman was recipient of a post-doctoral fellowship grant No 4803-04 from CEFIPRA. The 440 authors would like to acknowledge Dr. Phuong-Nhi Bories, Hôpital Cochin, Paris, for the 441 measurement of the toxicity markers. The authors are grateful to Dr. Claire Boulogne and Dr 442 Cynthia Gillet, IMAGIF Platform, Gif-sur-Yvette for measurement of the TEM, and Nicolas 443 Huangand and Monique Chéron for the help during the rheological and dichroism analysis, 444 respectively. 


\section{REFERENCES}

447 1. Kevric I, Cappel MA, Keeling JH. 2015. New world and old world Leishmania infections: A $448 \quad$ Practical Review. Dermatol Clin 33:579-593.

2. Frézard F, Monte-Neto R, Reis P. 2014. Antimony transport mechanisms in resistant leishmania parasites. Biophys Rev 6:119-132.

3. No JH. 2016. Visceral leishmaniasis: Revisiting current treatments and approaches for future discoveries. Acta Trop 155:113-123.

4. Chattopadhyay A, Jafurulla M. 2011. A novel mechanism for an old drug: amphotericin B in the treatment of visceral leishmaniasis. Biochem Biophys Res Commun 416:7-12.

5. Silva MA, Siqueira SDVD, Freire LB, Araujo IB, Silva KGDE, Medeiros AD, Araujo I, Oliveira AG, Egito EST. 2012. How can micelle systems be rebuilt by a heating process? Int J

6. Dea-Ayuela MA, Rama-Iniguez S, Sanchez-Brunete JA, Torrado JJ, Alunda JM, BolasFernandez F. 2004. Anti-leishmanial activity of a new formulation of amphotericin B. Trop

7. Petit C, Yardley V, Gaboriau F, Bolard J, Croft SL. 1999. Activity of a heat-induced reformulation of amphotericin B deoxycholate (fungizone) against Leishmania donovani. Antimicrob Agents Chemother 43:390-392.

8. Huang W, Zhang Z, Han X, Tang J, Wang J, Dong S, Wang E. 2002. Ion channel behavior of 

spectroscopy. Biophys J 83:3245-3255.

9. Cheron M, Petit C, Bolard J, Gaboriau F. 2003. Heat-induced reformulation of amphotericin B-deoxycholate favours drug uptake by the macrophage-like cell line J774. J Antimicrob Chemother 52:904-910.

10. Petit C, Cheron M, Joly V, Rodrigues JM, Bolard J, Gaboriau F. 1998. In-vivo therapeutic efficacy in experimental murine mycoses of a new formulation of deoxycholate-amphotericin B obtained by mild heating. J Antimicrob Chemother 42:779-785.

11. Stoodley R, Wasan KM, Bizzotto D. 2007. Fluorescence of amphotericin B-deoxycholate (fungizone) monomers and aggregates and the effect of heat-treatment. Langmuir 23:87188725.

12. Date AA, Nagarsenker MS. 2008. Parenteral microemulsions: an overview. Int J Pharm 355:19-30.

13. Damasceno BPGL, Dominici VA, Urbano IA, Silva JA, Araujo IB, Santos-Magalhaes NS, Silva AKA, Medeiros AC, Oliveira AG, Egito EST. 2012. Amphotericin B microemulsion reduces toxicity and maintains the efficacy as an antifungal product. J Biomed Nanotechnol 8:290-

14. Silveira WLL, Damasceno BPGL, Ferreira LF, Ribeiro ILS, Silva KS, Silva AL, Giannini MJM, Silva-Júnior AA, Oliveira AG, Egito EST. 2016. Development and characterization of a microemulsion system containing Amphotericin B with potential ocular applications. Curr 
15. Gaboriau F, Chéron M, Leroy L, Bolard J. 1997. Physico-chemical properties of the heatinduced 'superaggregates' of amphotericin B. Biophys Chem 66:1-12.

16. Audisio D, Messaoudi S, Cojean S, Peyrat JF, Brion JD, Bories C, Huteau F, Loiseau PM, Alami M. 2012. Synthesis and antikinetoplastid activities of 3-substituted quinolinones derivatives. Eur J Med Chem 52:44-50.

17. Stauber LA. 1958. Host resistance to the Khartoum strain of Leishmania donovani. Rice Institute Pamphlet - Rice University Studies. 45(80 - 96).

18. Purkait B, Kumar A, Nandi N, Sardar AH, Das S, Kumar S, Pandey K, Ravidas V, Kumar M, De T, Singh D, Das P. 2012. Mechanism of amphotericin B resistance in clinical isolates of Leishmania donovani. Antimicrob Agents Chemother 56:1031-1041.

19. Lawrence MJ, Rees GD. 2000. Microemulsion-based media as novel drug delivery systems. Adv Drug Deliv Rev 45:89-121.

20. Jain J, Fernandes C, Patravale V. 2010. Formulation development of parenteral phospholipidbased microemulsion of etoposide. AAPS PharmSciTech 11:826-831.

21. Pham TTH, Gueutin C, Cheron M, Abreu S, Chaminade P, Loiseau PM, Barratt G. 2014. Development of antileishmanial lipid nanocomplexes. Biochimie 107:143-153.

22. Silva AE, Barratt G, Cheron M, Egito EST. 2013. Development of oil-in-water microemulsions for the oral delivery of amphotericin B. Int J Pharm 454:641-648. of amphotericin B: spectral and microscopic analysis. BBA Biomembranes 1664:172-181. 

Gruszecki WI. 2014. Self-association of Amphotericin B: Spontaneous formation of molecular structures responsible for the toxic side effects of the antibiotic. J Phys Chem B 118:1382113832.

25. Fanos V, Cataldi L. 2000. Amphotericin B-induced nephrotoxicity: a review. J Chemother 12:463-470.

26. De Rycker M, Hallyburton I, Thomas J, Campbell L, Wyllie S, Joshi D, Cameron S, Gilbert IH, Wyatt PG, Frearson JA, Fairlamb AH, Gray DW. 2013. Comparison of a high-throughput highcontent intracellular Leishmania donovani assay with an axenic amastigote assay. Antimicrob Agents Chemother 57:2913-2922.

27. De Muylder G, Ang KK, Chen S, Arkin MR, Engel JC, McKerrow JH. 2011. A screen against

28. Gaboriau F, Cheron M, Petit C, Bolard J. 1997. Heat-induced superaggregation of amphotericin B reduces its in vitro toxicity: a new way to improve its therapeutic index.

29. Sarr SO, Perrotey S, Fall I, Ennahar S, Zhao M, Diop YM, Candolfi E, Marchioni E. 2011. Antimicrob Agents Chemother 41:2345-2351. PM. 2008. Selection of the most promising 2-substituted quinoline as antileishmanial candidate for clinical trials. Biomed Pharmacother 62:684-689. 
31. Gatto M, Abreu MM, Tasca KI, Simao JC, Fortaleza CM, Pereira PC, Calvi SA. 2013. Biochemical and nutritional evaluation of patients with visceral leishmaniasis before and after treatment with leishmanicidal drugs. Rev Soc Bras Med Trop 46:735-740.

32. Mbongo N, Loiseau PM, Billion MA, Robert-Gero M. 1998. Mechanism of amphotericin B 
a)

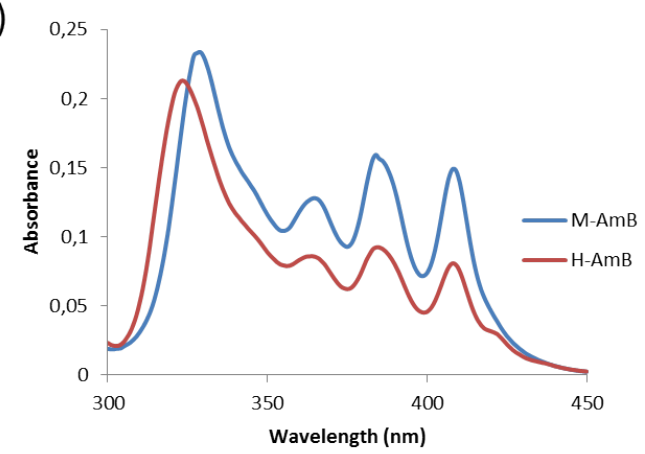

c)

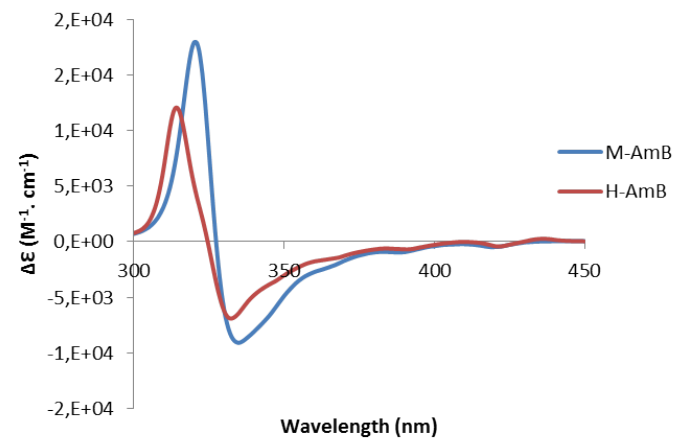

b) 0,3

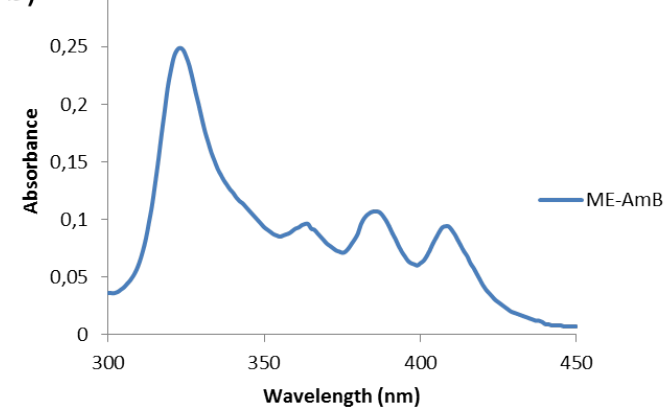

d)

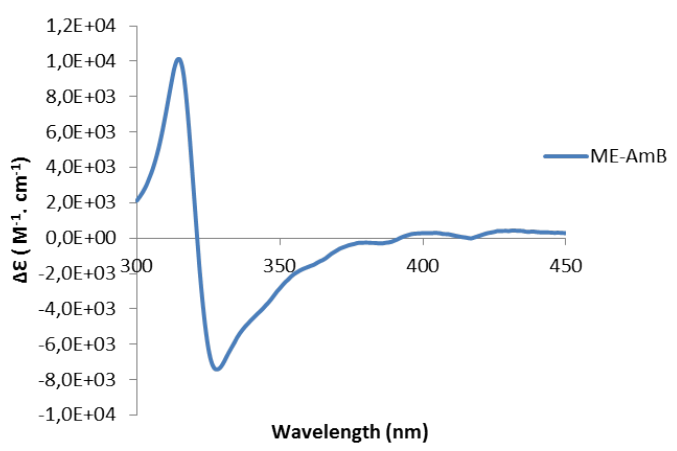

4 Figure 1: Spectroscopy of $\mathrm{M}-\mathrm{AmB}$ and $\mathrm{H}-\mathrm{AmB}$ (a) and of ME-AmB (b) and circular dichroism of M-AmB and H-AmB (c) and of ME-AmB (d). 

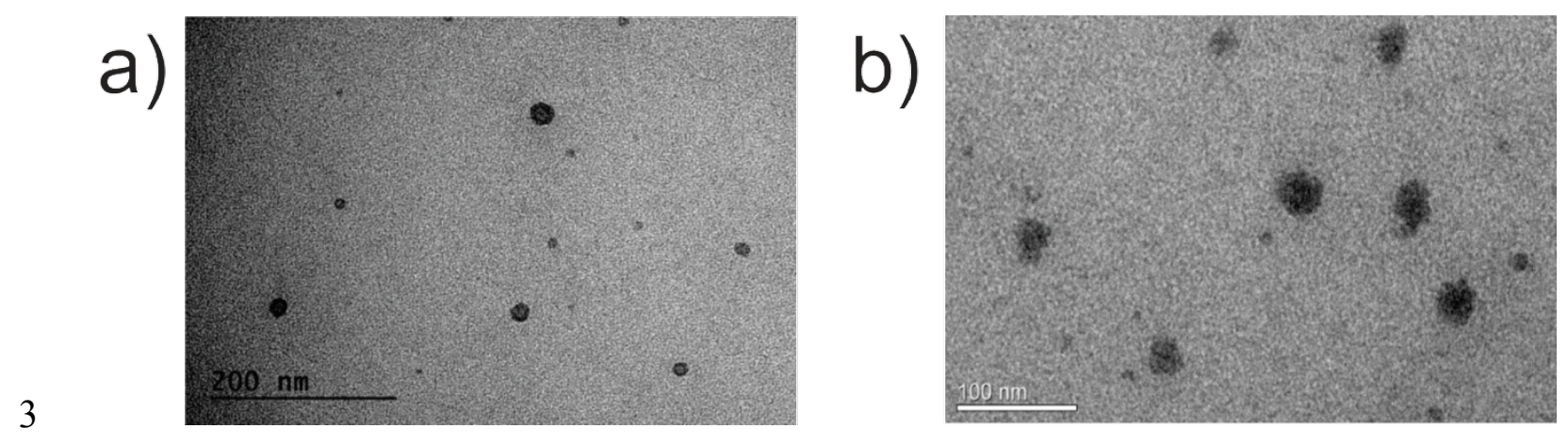

$4 \quad$ Figure 2: Transmission electronic microscopy of ME (a) and ME containing AmB (b). 


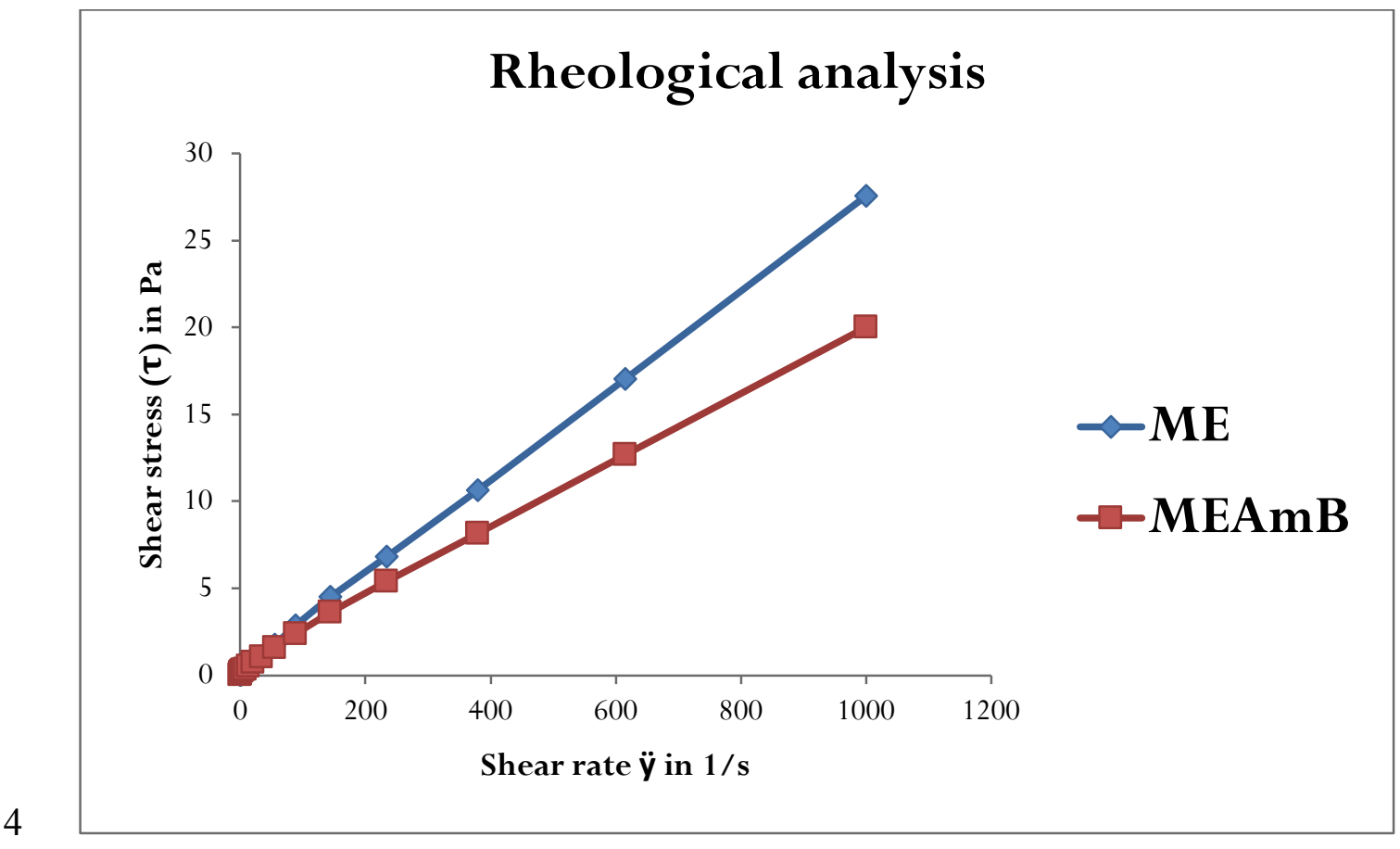
Figure 3: Rheological behavior of $\mathrm{ME}$ and $\mathrm{ME}$ containing AmB.

6

7

8

9 
1 Table 1: In vitro evaluation of the cytoxicity and the anti-leishmanial activity on L. donovani WT and AmB-R.

\begin{tabular}{|c|c|c|c|c|c|c|}
\hline \multirow[t]{2}{*}{ Formulations } & \multicolumn{2}{|c|}{$\begin{array}{l}\text { Intramacrophage amastigotes } \\
\qquad \mathrm{IC}_{50}(\mu \mathrm{M}) \pm \mathrm{SD}\end{array}$} & \multicolumn{2}{|c|}{$\begin{array}{l}\text { Axenic amastigotes } \\
\qquad \mathrm{IC}_{50}(\mu \mathrm{M}) \pm \mathrm{SD}\end{array}$} & \multirow{2}{*}{$\begin{array}{c}\text { Cytotoxicity } \\
\text { RAW } 264.7 \text { macrophages } \\
\mathrm{CC}_{50}(\mu \mathrm{M}) \pm \mathrm{SD}\end{array}$} & \multirow{2}{*}{$\begin{array}{c}\text { Selectivity index } \\
\mathrm{SI}=\mathrm{CC}_{50} / \mathrm{IC}_{50} \\
\mathrm{WT}\end{array}$} \\
\hline & WT & AmB-R & WT & AmB-R & & \\
\hline M-AmB & $0.06 \pm 0.01$ & $2.15 \pm 0.18$ & $0.05 \pm 0.01$ & $1.69 \pm 0.04$ & $4.5 \pm 0.4$ & 6.7 \\
\hline H-AmB & $1.53 \pm 0.33$ & $2.31 \pm 0.32$ & $0.05 \pm 0.01$ & $0.82 \pm 0.03$ & $39.8 \pm 3.2$ & 26.0 \\
\hline AmBisome ${ }^{\circledR}$ & $1.76 \pm 0.69$ & $3.54 \pm 0.10$ & $1.73 \pm 0.12$ & $>100$ & $36.5 \pm 2.3$ & 20.7 \\
\hline ME-AmB & $0.88 \pm 0.26$ & $1.56 \pm 0.01$ & $0.22 \pm 0.03$ & $3.38 \pm 0.08$ & $9.0 \pm 0.3$ & 10.2 \\
\hline ME & $28.01 \pm 2.70$ & $27.34 \pm 0.24$ & $6.82 \pm 0.72$ & $27.06 \pm 0.52$ & $22.8 \pm 2.9$ & 0.8 \\
\hline
\end{tabular}


1 Table 2: In-vivo antileishmanial activity and acute toxicity of $\mathrm{H}-\mathrm{AmB}$ and $\mathrm{ME}-\mathrm{AmB}$ compared to $\mathrm{M}-\mathrm{AmB}$ and $\mathrm{AmBisome}{ }^{\circledR}$. Mice were treated intravenously at $1 \mathrm{mg} / \mathrm{kg}$ equivalent $\mathrm{AmB}$ at Day 8, Day 10 and Day 12 post-infection.

\begin{tabular}{|c|c|c|c|c|c|c|c|}
\hline & & \multicolumn{6}{|c|}{ In vivo toxicity } \\
\hline & $\begin{array}{l}\% \text { Reduction of } \\
\text { parasite burden }\end{array}$ & $\begin{array}{l}{ }^{\mathrm{a}} \mathrm{AST} \\
\mathrm{U} / \mathrm{L}\end{array}$ & $\begin{array}{l}{ }^{\mathrm{a}} \mathrm{ALT} \\
\mathrm{U} / \mathrm{L}\end{array}$ & $\begin{array}{l}{ }^{\mathrm{b}} \mathrm{CHO} \\
\mathrm{mM}\end{array}$ & $\begin{array}{c}{ }^{\mathrm{a}} \text { CREA } \\
\mu \mathrm{M}\end{array}$ & ${ }^{\mathrm{b}} \mathrm{ALP}$ & ${ }^{\mathrm{b}} \mathrm{URE}$ \\
\hline M-AmB & 72 & 233.0 & 134.0 & $2.515^{* *}$ & 19.5 & 225.5 & 10.70 \\
\hline H-AmB & 78 & 189.5 & 171.5 & $2.575^{* *}$ & 18.0 & 241.0 & 9.65 \\
\hline AmBisome $^{\circledR}$ & 83 & 242.5 & 167.0 & $* 2.755$ & 20.0 & 229.0 & 10.15 \\
\hline ME-AmB & 78 & 224.5 & 169.5 & $2.415^{* *}$ & 18.5 & $246.0^{* *}$ & $8.35^{* *}$ \\
\hline ME & $* 33$ & 293.0 & 181.0 & $* 2.710$ & 16.0 & 225.0 & $* 7.60$ ** \\
\hline Untreated & - & 313.0 & 239.0 & 2.810 & 18.0 & $199.0^{* *}$ & $7.40 * *$ \\
\hline
\end{tabular}

5 AST: aspartate aminotransferase. Normal value: $456(\mathrm{U} / \mathrm{L})(30)$.

6 ALT: alanine aminotransferase. Normal value: 304 (U/L) (30).

7 CHO : Cholesterol. Normal value: $3.5 \mathrm{mM}(30)$.

8 CREA : Creatinine. Normal value: $<18 \mu \mathrm{M}(30)$.

9 URE : Urea. Normal value $7.4 \mathrm{mM}$.

* There was no significant difference in comparison to untreated $(\mathrm{P}>0.05)$

** There was significant difference in comparison to $\operatorname{AmBisome~}^{\circledR}(\mathrm{P}<0.05)$

a $\mathrm{P}>0.05$

b $\mathrm{P}<0.05$ 